\title{
What Did You Expect?
}

\section{Exploring the Roles of Clients' and Referrers' Expectations in the Success of the Music Therapy Process}

\author{
Susannah Wettone ${ }^{1 *}$ \\ 1 Non-affiliated, UK \\ *susannah@wettone.com
}

Received: 8 January 2020 Accepted: 6 January 2021 Published: 1 July 2021

Editor: Helen Brenda Oosthuizen Reviewer: Karyn Stuart-Röhm

\begin{abstract}
This article explores the ways in which the expectations of clients and referrers can impact the music therapy process. The setting is one of a self-employed music therapist working for a music therapy provider. The referrals for this therapist come from the community via the provider's website. A room in a community centre is used for sessions. Three case studies are presented, through which the relationship between the client's or referrer's expectations of music therapy and the actual outcomes of the work is explored. The first case study illustrates a scenario in which a client's expectations were different from what the therapist could offer, but an informed decision to continue music therapy on the part of the client was reached. The second case study considers how the communication between the therapist and referrer about the referrer's expectations enabled a client's needs to be met through a challenging therapy process. The third case study looks at how a previous experience of therapy for the referrer may have led to high expectations of the therapy for a client she referred. The paper examines how these expectations influenced the therapy process. The author argues that the expectations of the person referring a client can have a significant influence on the therapy process and must be accounted for.
\end{abstract}

Keywords: Expectations, therapeutic relationship, therapy process, assessment, client perspective

\section{Introduction - Music Therapy Referrals from the Community}

The music therapy provider for which I work comprises a coordinator and a team of thirteen self-employed therapists working with clients of all ages in schools, care homes and other community settings across the county and beyond.

I have worked for this music therapy provider for over ten years, primarily in schools and care homes. Referrals in these settings are made by other professionals, following general information and practical workshops offered by the music therapy 
provider. This helps to inform referrals and equip staff with a basic understanding of the approach and how they can best support clients attending music therapy.

In 2012, I began to take individual referrals from the community, to be seen in the therapy room in the provider's new premises. Without the procedures described above that promoted an understanding of music therapy and guided referrals, I found myself in a different position with regard to clients' and referrers' expectations about music therapy.

\section{Music Therapy Referrals and Assessment}

The referral process begins with an initial conversation between the potential client or referrer and the coordinator of the service. The client attends four assessment sessions, lasting between twenty minutes and an hour depending on the type of client and their needs.

At the beginning of the assessment, the reasons for referral are considered, alongside any other treatment and educational approaches, past and current. Some thought is also given to the timing of the referral within the context of the client's life. Wheeler and colleagues (2005) state that in music therapy assessments, music therapists "need to build an understanding of the client that helps [...] contextualise [their] music therapy assessment and subsequent goals of treatment" (p. 30). Entering into a potential therapy process requires practical and financial commitment from the client, referrer and/ or carer for it to work, so this needs to be explored carefully in this initial meeting.

The purpose of the assessment is for the client and me to try out using live, improvised music expressively and to see if this seems potentially helpful in addressing the client's needs. It is also important to explore ways of relating to each other and to see if it might be possible to build a trusting working relationship. It is an opportunity to notice the client's strengths and needs (Talmage \& Molyneux, 2014), respond musically and verbally to acknowledge and support these, and to determine the ways in which music therapy may be appropriate for them. Clients' and referrers' personal experiences of music, what it means to them, and how they perceive it as a therapeutic medium also have a part to play, and this can also be explored as part of the assessment.

The assessment format may not be exactly the same for each client. There is no single standard assessment method for music therapy in the UK (Churchill, 2015) and this is perhaps due to the necessarily individual nature of each client-therapist relationship. As part of her research into evaluation and assessment methods, Churchill (2012) has observed that when "therapists did use a formal process and tool, (they) found it necessary to continually adapt for best practice, with different approaches required according to reasons of referral" (p. 209).

The assessment is the opportunity for the interface between the client's or referrer's expectations and the expectations and recommendations of the therapist to be explored and negotiated. The therapist and client must be realistic about both the potential benefits and what is likely-or indeed unlikely-to be possible within the given time frame. I have found it increasingly necessary to be explicit about this, to encourage the client and/or referrer to prioritise their desired outcomes and to use the assessment to establish whether or not music therapy is the best way to achieve these outcomes. Reaching the initial conclusion of an assessment can be challenging, since there may be limits to how well a client and therapist will know each other at the end of an assessment. It is important to acknowledge that the assessment cannot be exhaustive in this regard.

\section{The Music Therapy Approach}

The music therapy approach I use is tailored to each client, but broadly speaking employs a model of improvised music making in which the therapist and client both take an active part. The beginning and ending of the session may be marked with a familiar song or activity for some clients, providing familiarity, predictably and reassurance as well as establishing and maintaining the boundaries of time of the session. 
Sloboda (1997) writes that "the professional training of music therapists stresses the role of improvisation in allowing individuals to express their emotional state, and to enter into an interactive dialogue with the therapist" (p. 121). I see my role as one of listening and responding to the client as they present themself musically and non-musically. It is helpful for the client to "be" without any rigid agenda and for me to see how they respond to this opportunity, to "free associate" musically and with their words, movements and other behaviours (Darnley-Smith \& Patey, 2003, p. 71). Pavlicevic (1997) describes shared improvisation in music therapy in this kind of approach:

By musically matching the qualities of the client's beating through improvising in a way that meets the client's rhythm, dynamic, timbre, tempo, rhythmic forms, the therapist is stating 'I acknowledge who and how you are.' (p. 151)

In my approach, the relationship is central to the therapeutic process (Association of Professional Music Therapists, 1990; Winnicott, 1982) and I make use of theories that draw parallels between early relationships and music (Stern, 1977) and the importance of early relationships (Winnicott, 1982). Such theories focus on the first relationship a baby has with their primary carer. The pre-verbal and intuitive nature of a parent-child relationship lends itself as a model for relating in music therapy with clients of all ages. In shared music making, I can attune to my clients, using my music to support them moment-to-moment, person-to-person in a way which is unique to our therapeutic relationship. I will now consider the beginning of the referral process for clients and referrers.

\section{What Happens Before Referrers and Clients make a Referral to Music Therapy?}

In my experience, clients from the community come to music therapy with very mixed background knowledge and understanding. The amount of research that clients and referrers do about music therapy-online or from leaflets, for example-varies. Doing a quick, general online search, as prospective clients and referrers might, I found a range of official websites, such as BAMT ${ }^{1}$ (British Association of Music Therapy), Nordoff-Robbins $^{2}$ and The Music Therapy Charity, ${ }^{3}$ which all gave similar explanations of music therapy and its benefits. My search also showed a range of information from a variety of other sources, countries and covering many different approaches.

It is evident from these sources that music therapy is portrayed as many different things online. It can take on various forms depending on the approach, techniques and stance of the therapist and their context. A search could be informative or misleading depending on its relevance to the potential client or referrer and how they interpret what they find.

Video footage of music therapy practice, now widely available online (Judd, 2013; Nordoff-Robbins, n.d.; Oldfield, 2014) is a powerful tool, showing the benefits of music therapy in action. It provides a snapshot of the therapist's approach and the desirable outcome, but the limitations of this may not be obvious to the viewer. Wheeler (2015) comments on the pitfalls of video footage of music therapy sessions and how they might be misinterpreted:

Because it is often enjoyable and people participating in a music therapy session may look as if they are having fun (which may very well be the case), sometimes the observer misses the clinical goals that are being worked toward of the therapy that is occurring. Even when music therapists try to educate others about what is actually occurring in music therapy, people do not always understand. (p.14)

If music therapists share clips online, portraying a client's responses of enjoyment and fun like this, are they setting up the expectation that significant moments in therapy occur all the time? Are the challenges faced by the clients and therapists downplayed as the viewer is swept away emotionally by a 'magic moment?' A short extract from one session, for example, is part of a process possibly spanning several months. 
The 'magic moment' needs its context in order to be fully appreciated. Might having improved general wellbeing as an outcome of music therapy be undervalued if expectations are of 'magic?'

Another consideration in exploring clients' and referrers' expectations is their own depth of understanding of the needs to be addressed. Transactional analysis psychotherapist Sills (2006) writes about different types of contracts for different clients and needs. She identifies that some clients may be unaware of some of the issues that are affecting them, and that these may only come to light as the therapy process unfolds. When asking clients and referrers to articulate their expectations, I have found that these expectations are not always clear. Referrers might speak of an enjoyment of musical experiences for the client, and the hope that this will be motivating for them. However, they often need my help to establish what the motivation generated through the musical experiences will be for and what changes they want to see in the client's wellbeing and daily life. Even when referrers describe their expectations clearly, it is often the case that other needs for the client may emerge through the assessment process. There will still be much work to be done in exploring these in depth within the context of the therapeutic relationship.

I have taken many community referrals which have been straightforward. Either the reasons for referral were clear and positive changes were observed, or it was clear both to me and the client or referrer that music therapy was not likely to be a helpful intervention for them. However, I have occasionally found that disappointment and apparent disillusionment about negative responses to therapy has led to endings which have felt untimely, and which could possibly have been avoided had expectations and understanding about what might happen been different. For example, I have found with a few parents that if their child has become distressed in the first session or early on in the assessment, this has not appeared to resonate with what has sometimes seemed to be an expectation that music therapy would be instantly fun and easy. Even when my interventions to address difficult behaviours or emotional outbursts have been successful, occasionally the mismatch between what was expected and what has happened has led to the parent's decision to discontinue music therapy sessions, sometimes even before the end of the assessment.

\section{Considering the Perspective of Clients and Referrers}

Much is written on the practice of music therapy in terms of its different models, approaches with various client populations (Bruscia, 1991, 2014; Bunt \& Stige 2014; Darnley-Smith \& Patey, 2003; Wheeler et al., 2015) and how music therapists communicate with their clients and other professionals (Procter, 2017; Twyford \& Watson, 2008). However, there appears to be a gap in the literature around the expectations of clients and referrers at the time of referral.

In the literature, some therapists consider how their referrers and clients experience, understand and interpret music therapy treatment. Annesley (2014) highlights the issue of an "institutional fantasy" - an expectation that a therapist working in a school will "fix" a child, in ways that may be idealistic (p. 41). He acknowledges the understandably strong desire of teachers to see improvements in pupils' behaviour. This desire can lead to the therapist being invited to "keep (the child) all day" or to address specific problems in sessions (p. 42). Roman (2016) explores the challenges faced by a therapist working in a school when "positive progress and [...] predictable outcomes" are expected (p. 20). For example, she describes how such expectations can affect how actual outcomes are perceived. This in turn, can influence decisions about future funding for music therapy.

Hibben's (1999) book, Inside Music Therapy: Client Experiences gives a direct voice to clients and how they see their treatment. The expectations of the clients are often described in the story of their therapy. For example, one parent shares her anxiety about how the therapist might view her child's behaviour (Jones \& Oldfield, 1999). In another chapter, a teenager expresses his resistance to the idea of "therapy," in contrast to 
his surprise at how well he was able to express himself in his sessions (Friedberg and Obstbaum, 1999). These insights into clients' and referrers' anxieties and misgivings about the experience of music therapy are helpful to consider when taking new referrals.

Bruce and High (2012) have explored how a child's music therapy was understood and interpreted by the child's parent and by other professionals in a school setting. For example, in the case study Bruce and High present, the occupational therapist and the physiotherapist state that music therapy was addressing their targets with the child. In contrast to this overlap, the teacher comments that the music therapy group is a "therapy bubble where educational targets do not come in and everyone can just be" (p. 72). Sometimes, music therapy might be perceived as overlapping with other disciplines in its objectives and at others it might be seen to be offering something different. This is another helpful point for consideration at the time of referral.

In addition, musical and instrumental improvisation is a vital component of my assessment process, clients and referrers may have questions and assumptions around this. Pavlicevic (1997) considers the client's experience of improvising with their therapist:

But what does the client listen to? And how? As therapists we have the benefit of a training that enables us to read the joint improvisation for what it may reveal. The client has no such training, and may well hear a blur of sounds, "noise" that is distressing, a 'nice wee tune,' and so on. (p. 162)

Reflecting on these different perspectives from clients, referrers and therapists, my focus at the beginning of a new referral should be to help the client and/or referrer to share what they want to change for the client through music therapy. I also need to consider what their anxieties about the process might be, what their experience of music is, and how we can work with that in a way that benefits them. This leads me to conclude that meticulous attention should be given to the client's understanding and initial experience of music therapy, both in terms of the information they are given before it begins and, in particular, during the assessment stage.

The case studies I will now present examine the relationship between client expectations and what I have been able to offer in music therapy. In all three cases, challenges were faced by the client, referrer and therapist. These included a difference between the expected benefits of music therapy and what I (and music therapy) could offer, responses in sessions that suggested that the client was struggling with the experience and a lack of music. All of these issues may have led to some clients or referrers concluding that music therapy was not for them. The questions I wish to consider are:

1. What developments took place in the relationship between expectations and actual outcomes of the clients and referrers during these case studies? and

2. How does this influence my current practice?

\section{Case Study 1 - Jim}

$\mathrm{Jim}^{4}$ was a man in his late fifties who had suffered a stroke and though recovering physically a year on, he was still struggling with aphasia. ${ }^{5}$ He lived with his wife, who cared for him and together they decided to look into music therapy primarily for communication needs. At our first meeting following the referral, I inquired about their initial expectations and it became apparent that a newspaper article based on the benefits of singing on speech development and recovery had prompted their referral.

At this initial meeting, I outlined benefits of music therapy and how these would be approached in the assessment. I explained that usually, the emphasis of my approach was on non-verbal expression, emotional support and the use of instruments as well as singing. With clients recovering from a stroke, Baker and Tamplin (2006) state that improvement of mood has been found through active improvisation and singing. These aspects of music therapy seemed new to Jim and his wife, so I considered that a fuller investigation of music therapy beyond the benefits of music was not something they 
had pursued. I gave them some more information in leaflet form (BAMT, n.d.) and asked if the other aspects of therapy I offered were of interest to Jim. He seemed open to this, but I noted that on the referral form, "communication" was the only area of need indicated.

The emphasis on improvements in speech development for this referral needed consideration. Jim had already had several months of speech and language therapy input and singing had been used as part of the treatment. What could music therapy add that had not already been offered in this area? The other aspects of building a therapeutic relationship and working to improve psychological and emotional wellbeing were areas that seemed appropriate to offer someone with Jim's needs, but I felt a responsibility to be clear about the nature of the treatment I could offer and to gain consent for this.

Over the four-week assessment, we tried some specific activities designed to help with words and speech. These were activities that Jim's speech and language therapist had suggested to me, to promote the flow of speech and finding words. We sang songs familiar to him and I accompanied on the piano. I could see that he was concentrating and trying very hard, with some success, but that some words were difficult for him to find. I also tried using a simple chord structure on the piano and adding words spontaneously-taking these from objects and furniture I could see in the room. Jim followed my lead, first repeating my words and then occasionally finding a word of his own. Jim engaged and worked very hard at this, appearing frustrated at times and surprised by the words that he managed to sing at others. During the first session he became tearful when we had been singing together. The struggle to use words seemed upsetting for him, and I wondered if the use of familiar songs might be a painful reminder of times when his speech was fluent and effortless.

I also offered the opportunity to play instruments and improvise together, with a view to providing some emotional support for Jim. Jim played the metallophone for sustained periods in the next few sessions and seemed to find this a satisfying and absorbing experience. I accompanied him on the piano and we created gentle, reflective pieces of music which seemed to balance the thinking and effort involved in trying to speak and find words. Jim seemed to relax in these improvisations, and he seemed pleasantly surprised by this.

At the end of the assessment I recommended continued treatment, identifying the speech-focused activities as well as the free improvisation as possible ways of working. Although Jim had found the speech-focused work emotionally and cognitively challenging, it did seem to help him to find and use words, and he was motivated to work at it. My report also described how Jim had seemed to respond to the free improvisation, and how this could be an opportunity for him to gain some emotional support and express himself through a different medium, in contrast to the more task-focused aspects of the other treatments he had had.

Jim's wife's comments on the assessment report interested me. She said that initially Jim had been sceptical about coming to music therapy, and after the first two sessions, had said he didn't think he would continue, but that he had "completely changed his mind" after the third session. This was the first session in which we had spent more extended time on free improvisation. I was particularly struck by the change in Jim's feelings about the sessions, as I too had felt this to be a turning point in terms of his use of the music and the way we were relating to each other. It seemed that Jim had experienced something unexpected but positive and that this experience had helped him to understand what else music therapy could offer.

Reflecting on this referral just over two years on, I consider what has changed in my thinking about the assessment of new clients. I was aware at the beginning of this referral that my approach could offer more than the client was asking. This assessment aimed to help him to understand and explore the other aspects of therapy I could offer and decide if it was what he wanted. In this case, my understanding that the use of freely improvised music without singing and working on speech could be helpful led to an exploration of this in the assessment. Had Jim not found this helpful, the options 
would then have been to work on speech-focused exercises, to explore other ways of using music (such as listening to recorded music) or not to pursue music therapy any further. I felt that through the assessment, I was able to explain and help Jim to consider the aspects of music therapy that he had expected alongside those that he had not expected. At the end of the assessment, he and his wife understood enough about what I could offer to make the decision to continue. They considered the emotional support that music therapy could offer through the assessment and chose to accept this as part of the therapy process. My work with Oliver highlights a different relationship between myself and the person who referred him to therapy.

\section{Case Study 2 - Oliver}

Oliver was referred for individual music therapy by his mother, Ann. He was five years old and coming to the end of his reception year at school. He had a diagnosis of Asperger's Syndrome. The reason for referral, as identified by Ann, was that music therapy would address Oliver's extremely active behaviour and help him to feel calmer. Ann felt that music could be helpful because it was something positive and motivating for Oliver. Ann rated the five areas of need on the referral form (on a scale of one to five, five being of highest importance) as follows:

$$
\begin{aligned}
& \text { Play skills - } 3 \\
& \text { Communication skills - } 4 \\
& \text { Social interaction - } 5 \\
& \text { Mood and behaviour - } 5 \\
& \text { Confidence - } 2
\end{aligned}
$$

She also added that Oliver had "difficulty listening to spoken words and obeying commands, fixed ideas, non-cooperation, difficulty recognising the role of authority e.g. teachers, parents." She noted that he experienced "anxiety if day is not planned using a timetable" and that he had "difficulty socialising and playing with other children and sensitivity to loud noises and bright lights."

I assessed Oliver over four twenty-minute sessions. Oliver engaged with me well and seemed to want to express himself and communicate with me. He was very lively, verbal and had many ideas about how to use the instruments and the room. He was very directive towards me and the way he communicated with me seemed to indicate a mixture of desire to connect and play with me, and to be in control.

During the assessment, I considered the potential areas that Oliver might need help with, in terms of his diagnosis of Asperger's Syndrome ${ }^{6}$. Feeling anxious about unpredictability and change and exhibiting "rigid and repetitive patterns of activity and play" are common in people with an autistic spectrum condition (Wigram, 2002, p. 13). This informed my approach, which aimed to balance accepting, listening and responding positively to Oliver's sounds and other behaviours, and also maintaining boundaries and my own identity as a separate individual who can act independently. To comply unquestioningly with his every demand risked collusion with his desire to be in control. This way of maintaining boundaries is described by Tyler (2003), who explains how she doesn't allow a child to take her (the therapist's) shoes off or braid her hair, identifying the importance of respect and boundaries in the relationship. However, I also needed to help him feel safe and earn his trust in order to help him work on these difficulties. I felt that he needed to know that I was listening to him and caring about him. Once this was established, I looked for opportunities to challenge Oliver's tendency to control when it seemed he could cope with this.

At the end of the assessment I recommended ongoing weekly sessions. Considering the reasons for referral and my experience of Oliver in the sessions, I recommended three areas of focus, which were discussed and agreed with Ann: First, to help Oliver to develop his existing capacity to use music and words to express himself; second, to help him to tolerate input from me that was not only directed by him; and third, to 
work towards him becoming more flexible in his use of instruments and play generally.

\section{Continuing Therapy}

Oliver continued to communicate and express himself, using the instruments and talking, but often found my input difficult to accept. He was resistant if I tried to do more than acknowledge that I was hearing and seeing the ideas and emotional content he brought. There were times when he engaged in role play, acting out frightening scenarios involving explosions and other dangerous situations. When these emerged, there was often little or no music, sometimes for a number of consecutive sessions at a time. It seemed to me that these situations represented his anxiety about situations he found challenging.

I considered what was occurring in the countertransference. My own feelings in the sessions were of powerlessness, self-doubt and inadequacy. I explored these in supervision and this enabled me to make sense of them in relation to Oliver's feelings and to feel more grounded in my approach. I felt I needed to provide a containing presence and to witness, receive and acknowledge the feelings associated with Oliver's play. Bion (1962) writes about the parent as a "container" for the child's chaotic or frightening experiences. The parent is not overwhelmed by them and helps the child to bear them. Oliver couldn't bear very much musical or verbal response from me, but I was able to hold onto my role as a receiver and container and not underestimate the value of the small amount of response that he could tolerate.

Ann and I spoke on the phone every few weeks about Oliver's progress in and out of the sessions. Ann was keen for me to communicate with Oliver's school, and she and I both attended school team discussions about Oliver's needs and progress. As a result, Music Therapy formed a valuable and integral part of Oliver's support package. Ann's expectation of these lines of communication being in place really supported and facilitated the therapy process. It was possible to share constructively the challenging aspects of the sessions with Ann, even when the sessions were very difficult for Oliver and for me. She welcomed and did not seem surprised by the amount of communication with her that I offered. I was really struck by Ann's resilience and acceptance of the difficulties. Some years after the therapy ended, I asked Ann how she managed to cope with this. She said that she was experiencing negative feedback in all the settings Oliver was in particularly at school. She highlighted support from other parents with children with similar needs as very helpful with coping with this. It seems that she aligned music therapy with the other help that Oliver was receiving and did not expect its benefits to be magical or instant.

When I asked Ann how she felt about the non-musical use of the sessions, she said that whilst she had hoped Oliver would use the sessions musically because he loved music, she could see that he was still engaging with me and she seemed to understand that our working relationship was helping him. He was enthusiastic about the sessions and they seemed important to him. Although this may not have fitted with her original expectations, she was able to see the positive aspects of the process at work.

\section{The Decision to Finish Therapy}

After almost two years of music therapy, Oliver had made significant progress in the areas I identified at the end of the assessment. He was calmer in the sessions, more able to accept input from me and it seemed that he was more able to manage his anxiety. Ann also highlighted that Oliver's increased acceptance of my input had generalised into other settings, and that this was unexpected. He had become more able to accept input from other adults as well as me. She acknowledged that in this regard, the benefits of music therapy had exceeded her expectations.

Ann and I came to a mutual decision for him to finish his therapy at the end of year 2 at school. This coincided with Oliver moving up from the infants to the juniors. Ann 
felt that it marked a positive point in his process of growing up and moving on and I agreed.

The challenges faced during this process of effective therapy could have led some parents of prospective clients to become sceptical about its benefits. The fact that Ann appeared to trust me and the process despite its emotional challenges became the subject of deeper thought and consideration for me. The fit between Ann's and Oliver's expectations and my approach facilitated the process through these challenges. I will now describe a case in which the referrer's expectations were, I believe, influenced by her own experience of therapy and hopes for similar outcomes for the client.

\section{Case Study 3 - Jodie and Tracy}

A Special Educational Needs Co-Ordinator (SENCo) in a school referred a nine-year old girl, Jodie, and her mother Tracy, for music therapy. Jodie had a diagnosis of Pathological Demand Avoidance (PDA) and was exhibiting oppositional and challenging behaviour at school. Jodie was from a large family and the SENCo was concerned that she needed more individual attention from her mother. The reason for referring Jodie and Tracy to come to the sessions together was to offer some protected time for Tracy and Jodie to relate to each other without any other demands or distractions. In this case study, the parent of the client (this time, not the referrer) did not engage in the process with me in the way that Ann did. The challenge with this piece of work lay in the fact that the referrer had high expectations and hopes for music therapy, but these were not shared and understood by the parent. This meant that the parent was not committed to the therapy process, and this impacted significantly on the process.

I was aware that the SENCo who referred Jodie to therapy had had a personal experience of art therapy and had found this had helped her to bond with her adopted child when they had attended sessions together. She felt that Jodie needed some protected time for shared experiences with her mother and hoped that music therapy sessions could provide this. The motivation for the referral could be seen in part as a response to her own helpful experience of parent-child bonding through a creative therapy. Another perspective is possible feelings of hopelessness about the Jodie's behaviour and a wish that I, the therapist working with the parent, would "fix" this in the way that Annesley (2014, p. 41) suggests earlier in this paper.

I felt optimistic that the SENCo seemed to believe in and have some understanding and experience of a creative therapeutic approach. However, I also felt concern that I might fail to deliver this "good therapy" that she had in mind, as her expectations seemed high.

The reality of this piece of work was that although Jodie's mother, Tracy, attended all of the assessment sessions and seemed very motivated to continue at the end of the assessment, she did not commit to attending the sessions regularly going forward. When the therapy was reviewed after a few months, I decided that this model of working was not viable. This is an example of a discrepancy between expectation and outcome which had a significant impact on the direction of the therapy thereafter. Without Tracy's commitment to attend the sessions, what could or should be offered to Jodie? Jodie did not seem to show me how she felt about Tracy's absence. I was conscious of my own frustration at Tracy's lack of commitment. Together with Jodie, I considered that it seemed difficult for Tracy to come every time but did not encourage Jodie to explore how it made her feel. The SENCo was keen for the work to continue, for Jodie to attend sessions on her own and have a supportive and creative space and individual attention. I suggested this to Jodie, and she agreed to continue, although she did show ambivalence and resistance to coming to the sessions and in her interactions with me in the room. Relating these behaviours to Jodie's diagnosis and needs, rather than allowing her to push me away I wanted to support her. Thus I worked individually with Jodie for several months after Tracy stopped coming to the sessions.

I felt that the disappointment felt by the SENCo that this process did not work out as she had hoped impacted on her expectations of the continuing work. When there were 
significant challenges such as a lack of engagement, a lack of musical participation, and resistance to attending the sessions, I felt that she struggled to see the value of the continuing work. Upon reflection, I wonder how much of this struggle was to do with the contrast between Jodie's therapy process and her own therapeutic experience with her child.

\section{Reflections on the Expectations of these Referrers}

I have reflected on what these clients and referrers seemed to expect and how this affected the way I worked with them. The starting point for our work in all of the cases was a specific outcome. For Oliver it was a desire for Oliver to feel calm, for Jim, improvement in his speech and expressive language and for Jodie, a closer bond with her mother which could in turn help her to feel more able to cope with the challenges of school life. The alignment of these initial referral reasons and my music therapy approach could be seen as pivotal to the decisions made at the end of the assessment. In all of the cases, at the end of the assessment, the clients, referrers and I agreed that it was realistic to expect improvement in the area that concerned them the most. With Jim and Oliver, this shared understanding may have provided the reassurance and trust needed for me to recommend other areas of focus. I felt in a strong position to communicate that the main referral reason for both clients was just one possible benefit of the therapy process and to encourage exploration of others. With Jodie, during the assessment the engagement and commitment from Tracy seemed to indicate that it would be realistic to expect outcomes in line with the reasons for referral. It was only as the process unfolded and this commitment was tested that it became apparent that this was not the case. This is an example of how a lack of alignment between the expectations and perceptions of the referrer, the client, and in this case the carer as well, can affect the potential for the therapy to achieve the desired outcomes of the referral. It also demonstrates that plans made at the end of an assessment may not unfold as expected, even if the evidence from the assessment suggests otherwise.

\section{Exploring Expectations with Clients and Referrers}

It is understandable for clients and referrers to want to see and experience beneficial outcomes in music therapy. However, when a resistive or disinterested response, particularly in the initial sessions, leads to the client's or referrer's assumption that music therapy is not suitable for the client, it can be a challenge to help the client or referrer to remain open to the idea that music therapy could be of benefit. Wheeler et. al. (2005) identify that assessing suitability of music therapy is "context bound":

In some clinical situations, the behaviors and responses of clients may be an indicator that the client is not suitable for music therapy, whereas in others, these same behaviors may be manifestations of the client's therapeutic issues, which can then be observed and assessed within various kinds of musical experiences [...]. (p. 43)

For me as a music therapist and for some referrers like Ann, the notion that sessions do not always go as expected and that behaviours are an indicator of the client's emotional state, is understood. However, in my experience, for clients and for referrers in particular, it would seem that sometimes it is not clear. The challenge here lies in helping the referrer to think about the client's response in terms of the client's needs rather than assuming that music therapy will not be appropriate for them. I must always be aware that a referrer knows the client much better than I do at the assessment stage and I must listen to their concerns. At the same time, however, I must consider the referrer's emotional experience of the client. Particularly if they are a close family member, their view of the client may not be objective. Indeed, their own emotional vulnerability around the client and their struggles bears careful consideration. For example, Bicknell (1983) describes how a parent experiences emotions including grief, loss, denial, guilt and anger initially and throughout the life of their child with a disability. 
It seems sometimes that the referrer may be embarrassed by the client's behaviour. Indeed, this may have been the case at times for the referrers in the case studies I have presented. For example, I wondered if Ann felt embarrassed by Oliver's resistance to my interventions (and she expressed concern to me about this at first). However, for some referrers, rather than embrace the struggle to accept it, particularly in front of me, it may be easier to abandon music therapy or assume that it is the music therapy situation that has caused the difficult response.

It is my job to demonstrate and explain how a client's needs could be addressed through music therapy, an area which is likely to be new or less familiar to the referrer. I also have a responsibility to be clear about what music therapy cannot address and explain this if the referrer has expectations which are not realistic. I may feel defensive if a client or referrer has misgivings about music therapy, so a conscious step should be taken to encourage dialogue about their initial impressions and how these compare with their expectations. If behavioural difficulties, for example, can be identified as "manifestations of the client's therapeutic issues" (Wheeler et al., 2005, p. 43), as Wheeler and colleagues suggest, the assessment recommendations should explain how music therapy might address the issues. For example, if a client who has been referred for help with their anxiety is reluctant to come into the room, I might interpret this as a manifestation of their anxiety. My interventions would address this. I would start where the client is-physically, musically and emotionally. After acknowledging this musically and/or verbally, I would explore ways of supporting them to help them to feel able to come into the room.

My responses to some clients' resistance and reluctance may not always be what referrers expect. This can be a problematic issue, particularly if good communication between the referrer and me is not established early on. Roman (2016) describes her process of understanding what might be happening for a client, but identifies the difficulties communicating this to the referrer. She describes how the referrer's understanding of the client's behaviour (in this case, the client refusing to come to the session), is different from her own understanding. She writes about making use of her countertransference feelings to inform her interventions, explaining that although the referrer (a teacher) "accepted [her] rationale," it was "extremely difficult for [her] to communicate why this was valuable" (p. 19). The tension and difficulty in the role of the music therapist here is sharing an opinion which is informed by theoretical concepts which are likely to be unfamiliar to the referrer.

It is important to acknowledge these challenges, but alongside this I can draw on my experience to support the client and referrer. I will not have experienced every situation before, but clients' resistance, distress and indifference are familiar to me and I can provide reassurance that I have resources to address these responses.

There are times, however, particularly during the assessment, when it is not clear to me what is best for the client. What is needed from me when I, the client, and the referrer may all be feeling discomfort and uncertainty around meeting the client's needs through music therapy? A helpful place to start could be to acknowledge the discomfort and offer reassurance that sometimes assessments are not straightforward. I can offer a conscious acknowledgement of the difference between what the referrer or client hoped for and what is happening and offer support with this. Perhaps an active framing of the assessment as a period of 'not knowing' for all concerned is helpful and can be emphasised more at the time of the referral. Can I consciously and actively model openness in my own expectations that I will help the client and/or referrer to stay with the process when it is difficult?

It is just as important to create a space for 'not knowing' when a client responds very positively in their assessment sessions. It is encouraging, of course, to see a client express themself freely, respond to my musical support and perhaps 'come alive' in a way that is rare in other situations. However, this is no more a 'quick fix' for their difficulties than a negative response may be a contraindication for music therapy. Bearing in mind the emotional vulnerability of referrers who are close to the client, an initial positive reaction may appear to promise an unrealistically quick and easy pathway to 
the desired therapeutic outcomes. My job is to accept the "whole client" (Talmage \& Molyneux, 2014, p. 201) and what may emerge in the therapy process and help them do the same, bearing in mind that the "whole client" and the reasons for their referral may be present and observable only to a limited degree during the assessment.

\section{To Explain or to Experience?}

In my opinion, written or spoken words are limited in enabling the client or referrer to understand the process. This may be partly due to the difficulty of using words to explain a musical process, which will inevitably lose something of its essence in the 'translation.'

The way in which a therapeutic relationship is built, moment to moment, in and out of the music can be just as difficult to capture and explain. Again, Sills (2006) considers what too much detailed explanation of a verbal therapeutic approach may take away from the experience:

[...] many practitioners feel that to describe the process in detail is like describing the film before you get to the cinema. [...] In that case, the therapist must weigh up the balance between an ethical obligation to make sure the client is well informed about what he is 'letting himself in for' and the desire to keep the field open to surprise and spontaneity.

(p. 20)

So, there is value in enabling a client to experience without a detailed explanation of everything I am doing. At the same time I try to give enough information about what I am trying to help the client with (when necessary and not off-putting) for them to feel informed and supported. For example, with Jim, I often built in comments about what I was doing before playing music with him and then commented and reflected about it afterwards. I encouraged him and his wife to share their thoughts and ask questions if they were feeling unsure about anything. Explaining and experiencing can work together and feed into each other through the assessment process.

\section{Communication and Teamwork}

Another factor crucial to the success of a music therapy process is communication with other professionals involved in the care and treatment of the client. The therapist working in isolation in the community is reliant on the cooperation of the client or referrer to liaise with other members of the team in order to ensure that their approach is informed by and not in conflict with other aspects of the client's care and treatment. Richards (2007) identifies the problems that can occur when good communication is not possible:

People with complex needs are at risk of that complexity being reflected in fragmented clinical treatment, with psychiatrist, psychologist, dietitian and social worker, for instance, each attending to a particular area of concern, but in insufficient communication and debate with one another. There is a danger of music therapy also becoming part of that unsatisfactory pattern [...]. (p. 69)

The communication with the clients' referrers and other professionals was good in the first two case studies described and both referrers assumed that my involvement and communication with the whole team would be a part of the work. I found with Jodie, that although my attendance at team review meetings was accepted, I suggested this rather than automatically being invited. I have found that this is not uncommon. Even though the necessary consent for this is sought at the beginning of the referral, it can be difficult to achieve integration into the team if it is not what clients and referrers are expecting as part of the service. Attention to this at the time of the referral is something I have come to prioritise in every assessment situation. 


\section{The Impact on Practice}

Encountering the assumptions of clients and referrers, which form the basis of their expectations, is an inevitable and complex part of the referral and assessment process and the therapy process as a whole. It leads me to question how to take steps to avoid missing such assumptions, which may then impact on the process.

Reflecting on these three case studies, I consider how what I have learnt now informs my practice. Jim's case illustrates that it is possible to find a path to successful therapy even when a client's original expectations are different from the scope of what music therapy can offer. Oliver's case illustrates the resilience of the client and/or referrer and their readiness to weather the potential storms that a therapy process might entail. I could argue that for Ann and for Oliver, this resilience was something they both came with, but perhaps more robust support is needed for some clients, like Jodie and Tracy. This could mean space for reflection and encouragement to share their responses and ask questions if they are feeling uncomfortable or unsure about the assessment process. The assessment should include preparation for therapy as a treatment to address goals, which may be difficult at times, particularly if the client and/or referrer has expectations of fun and pleasurable experiences.

Identifying specific aims and objectives as part of the assessment and reviewing these regularly has always been embedded in my practice, but with the community referrals, sometimes reviewing the process and communication with the client and /or referrer took place somewhat informally. Currently, review meetings are built into each therapy agreement on a more frequent and formal basis. Setting up this expectation as the therapist from the beginning promotes consideration of desired outcomes that is not rushed, more mutually negotiated and understood, and more likely to be realistic and achievable.

Miller (2014) highlights the benefits of ongoing assessment in the therapy process, but identifies that it can be "an informal and internal process which may lack [ ... ] clear clinical direction and which may limit communication with the client and with the other professional people involved" (p. 17). To avoid this lack of direction, she advocates a "structure and rationale to this process" which can "increase confidence for the therapist and the client" (p. 17).

Since the work I did with the clients in these case studies, in order to ensure we have a structure and a rationale to the assessment process, the team of music therapists working for the service provider that I work for make use of outcomes tools. Although tools can have limitations, such as providing a simplified picture of the progress made and failing to explain the circumstances of set-backs, (see Roman, 2016), I find these can help to provide clarity about what the therapy is for and this can help to dispel misconceptions.

I consider the 'fit' between client or referrer expectations and what music therapy itself, and I as the music therapist, can offer. This will be naturally closer and more aligned with some clients than others. It is not realistic to expect that I can anticipate all of the assumptions that people make about music therapy: However, I can keep an open mind to their existence and be explicit about the process in an accessible way. I can also encourage the client or referrer to pause with me and for us both to give attention to their expectations and the extent to which music therapy can meet them.

My thinking about new referrals has shifted over the years. In the earlier part of my career, I was more focused on my impressions of a client and what I felt I could offer them. I have become much more focused on the interface between the music therapy I offer and the hopes and expectations of referrers and clients. The referral form is an important starting point for an assessment, but it is a brief and relatively simplistic presentation of a client whose needs are likely to be complex. Therefore, the work of the assessment lies initially in the dialogue about the client and/or referrer's understanding of what they are asking of me and my ability to highlight what of that, and if appropriate, what else, I think it is possible for me to deliver. The assessment is then the opportunity for the client and I to see if we can work together. For the therapy 
to work to its fullest potential, we need to agree on aims for the therapy, to align our expectations about the potential challenges and ensure robust methods of review and communication outside the sessions themselves. We may or may not then be working in a way that the client or referrer has originally expected.

\section{Acknowledgements}

I/the author would like to thank Veronica Austin, Paul Ramsay and Rebecca Longley for their input and encouragement in the earlier stages of writing this paper.

\section{About the Author}

Susannah Wettone graduated as a music therapist from Anglia Polytechnic University (now Anglia Ruskin University) in 1999, completing her MA in music therapy in 2001. She began her career as an employed music therapist in special education. She has also worked in the NHS in adult mental health. Since 2004 she has worked for a music therapy provider in South East England. She has worked with adults and children in a variety of settings, such as schools, hospitals, day centres and residential homes as well as taking referrals from the community. Susannah has an interest in communication with referrers and the wider multi-disciplinary team and enjoys supervising music therapy students on placement. Her main areas of experience over the last few years are autistic spectrum conditions, pre-school children and, more recently, music therapy for parents and children.

\section{Notes}

1. https://www.bamt.org/

2. https://www.nordoff-robbins.org.uk/

3. https://www.musictherapy.org.uk/

4. The author confirms that written permission has been given by all those described in the case studies in this paper. Names have been changed to protect their confidentiality.

5. Aphasia is a disorder in which "speech output is affected as a result of the brain's difficulty with formulating and/or interpreting words and sentences" (Baker \& Tamplin, 2006, p. 144)

6. The term "Asperger Syndrome" is no longer used. The Diagnostic and Statistical Manual of Mental Disorders (DSM-IV) added Asperger Syndrome in 1994 as a separate disorder from autism, but placed the collection of symptoms fitting this diagnosis within the umbrella term "autism spectrum disorder" in 2013 in the DSM-5. This referral, however, was made in 2012, before this change was made.

\section{References}

Annesley, L. (2014). The music therapist as outsider. The British Journal of Music Therapy, 28(2), 36-43. https://doi.org/10.1177/135945751402800207

Association of Professional Music Therapists (APMT). (1990). A career in music therapy. APMT Publications.

Baker, F., \& Tamplin, J. (2006). Music therapy methods in neurorehabilitation: A clinician's manual. Jessica Kingsley Publishers.

Bicknell, J. (1983). The psychopathology of handicap. The British Journal of Medical Psychology, 56, 167-178. https://onlinelibrary.wiley.com/doi/abs/10.1111/ j.2044-8341.1983.tb01544.x

Bion, W. R. (1962). A theory of thinking. International Journal of Psychoanalysis, 43, 306-310.

British Association of Music Therapy (BAMT). (n.d.). Music therapy and neurodisability. A brain changer. Retrieved 23 January, 2018, from www.BAMT.org 
Bruce, A. \& High, S. (2012). Multiple views on music therapy. In J. Tomlinson, P. Derrington \& A. Oldfield (Eds.), Music therapy in schools: Working with children of all ages in mainstream and special education (pp. 61-74). Jessica Kingsley Publishers.

Bruscia, K. (1991). Case studies in music therapy. Barcelona Publishers.

Bruscia, K. (2014). Defining music therapy (3rd ed.). Barcelona Publishers.

Bunt, L., \& Stige, B (2014). Music therapy: An art beyond words (2nd ed.). Routledge. https://doi.org/10.4324/9781315817989

Churchill, V. (2015). What do we do? Music therapy and assessment: Considerations for $21^{\text {st }}$ century practice. Approaches: An Interdisciplinary Journal of Music Therapy, 7(2), 207-211.

Churchill, V. (2012). Creating a music therapy assessment tool specific to persons with severe to profound multiple disabilities [Unpublished master's thesis]. The University of Melbourne.

Darnley-Smith, R., \& Patey, H. (2003). Music therapy. Sage Publications.

Friedberg, A. J., \& Obstbaum, L. (1999). Family day: An interview with a family. In J. Hibben (Ed.), Inside music therapy: Client experiences (pp. 77-82). Barcelona Publishers.

Hibben, J. (Ed). (1999). Inside music therapy: Client experiences. Barcelona Publishers.

Jones, A., \& Oldfield, A. (1999). Sharing sessions with John. In J. Hibben (Ed.), Inside music therapy: Client experiences (pp. 165-171). Barcelona Publishers.

Judd, R. (2013, April 1). How does music therapy benefit children with special needs? (Video). YouTube. https://youtu.be/wXcmWwSQGI4

MacKeith, J., Burns, S., \& Lindeck, J. (2011). The music therapy star: The outcomes star for children in music therapy. Brighton Triangle Consulting Social Enterprise.

Miller, C. (2014). Overview. In C. Miller (Ed.), Assessment and outcomes in the arts therapies: A person-centred approach. Jessica Kingsley Publishers. https://www.tandfonline.com/doi/abs/ 10.1080/02630672.2015.1012362

Nordoff-Robbins. (n.d.). Stories. Retrieved 16 December, 2020 from https://www.nordoffrobbins.org.uk/stories/

Oldfield, A. (2014, July 30). Music therapy at Addenbrooke's Child Development Centre. Anglia Ruskin University. (Video) YouTube. https://youtu.be/LzyYWSwyvSY

Procter, S. (2017). Music in mind. SEN, 87, 22-24.

Pavlicevic, M. (1997). Music therapy in context. Jessica Kingsley Publishers.

Richards, E. (2007). 'What bit of my head is talking now?' Music therapy with people with learning disabilities and mental illness. In T. Watson (Ed.), Music therapy with adults with learning disabilities (pp. 58-70). Routledge.

Roman, T. (2016). Were they better today? Valuing a client's individual therapeutic process within an institution's expectations of positive progress and predictable outcomes. The British Journal of Music Therapy, 30(1), 13-21. https://doi.org/ $10.1177 \% 2 \mathrm{~F} 1359457516636317$

Sills, C. (2006). Contracts in counselling and psychotherapy. Sage Publications.

Sloboda, A. (1997). Music therapy and psychotic violence. In E.V. Welldon and C. Van Velsen (Eds.), A practical guide to forensic psychotherapy (pp. 121-129). Jessica Kingsley Publishers.

Stern, D. (1977). The first relationship: Infant and mother. Harvard University Press.

Talmage, A., \& Molyneux, C. (2014). Individual music therapy for an adolescent with severe cerebral palsy. In C. Miller (Ed.), Assessment and outcomes in the arts therapies: A person centred approach (pp.186-203). Jessica Kingsley Publishers.

Twyford, K., \& Watson, T. (2008). Integrated team working: Music therapy as part of transdisciplinary and collaborative approaches. Jessica Kingsley Publishers.

Tyler, H. (2003). Being Beverly: Music therapy with a troubled eight year old girl. In S. Hadley (Ed.), Psychodynamic music therapy: Case studies (pp. 37-51). Barcelona Publishers.

Wheeler, B. (Ed.). (2015). The music therapy handbook. Guildford Press.

Wheeler, B., Shultis, C., \& Polen, D. (2005). Clinical training guide for the student music therapist. Barcelona Publishers. 
Wigram, T. (2002). Indications in music therapy: Evidence from assessment that can identify the expectations of music therapy as a treatment for Autistic Spectrum Disorder (ASD); meeting the challenge of evidence-based practice. The British Journal of Music Therapy, 16(1), 11-28. https://doi.org/10.1177\%2F135945750201600104

Winnicott, D. W. (1982). Playing and reality. Routledge. 